\title{
Alterations in Chromatin Structure Associated with Glucocorticoid- Induced Expression of Endogenous Mouse Mammary Tumor Virus Genes
}

\author{
DAVID O. PETERSON \\ Department of Biochemistry and Biophysics, Texas Agricultural Experiment Station, Texas A \& M University, College \\ Station, Texas 77843
}

Received 2 November 1984/Accepted 14 February 1985

\begin{abstract}
Alterations in the chromatin structure of endogenous mouse mammary tumor virus genes accompany glucocorticoid induction of viral RNA synthesis in the C57BL/6 T lymphoma cell line T1M1. These alterations are defined by the appearance of sites of DNase I hypersensitivity within proviral DNA in isolated nuclei, as well as by changes in the moderate nuclease sensitivity of entire proviral transcription units. Induced hypersensitive sites, termed type I, appear with a time course comparable to that required for induction of the rate of viral RNA synthesis and are maintained only in the continuous presence of hormone. Two such sites map to analogous positions in the $5^{\prime}$ and $3^{\prime}$ long terminal repeats of proviral DNA within, or very near, sequences that have been shown to comprise positions of specific binding of the glucocorticoid receptor in vitro and that are required for hormone-inducible transcription in vivo. A third type I site maps to another position of in vitro receptor binding near the $3^{\prime}$ long terminal repeat. Some sites of DNase I hypersensitivity, termed type II, appear not to be markedly hormone dependent; two such sites are present in corresponding positions in each long terminal repeat. Comparison of the moderate DNase I sensitivity of mouse mammary tumor virus proviral DNA suggests that the three different endogenous units in T1M1 cells can be maintained in distinct chromatin conformations that are determined by factors related to the site of provirus insertion. It seems possible that altered chromatin conformations may reflect, or actually encode, important mechanistic features of these hormone-responsive genes.
\end{abstract}

The RNA genome of mouse mammary tumor virus (MMTV), a retrovirus, is encoded by proviral DNA covalently integrated into the nuclear DNA of infected cells. Glucocorticoid hormones rapidly and selectively activate transcription of these proviral genes by a mechanism that requires functional glucocorticoid receptor proteins (13) and results in an increase in the frequency of transcription initiation at sites that are identical to those that are used with lower efficiency in the absence of hormone $(29,36)$. In vitro, purified glucocorticoid receptor protein has been shown to bind specifically to a 340-base-pair (bp) restriction fragment from the MMTV long terminal repeat (LTR) $(10,12,25,26$, $28,31)$. This fragment, termed the glucocorticoid response element (GRE), is able to confer hormone inducibility on heterologous promoters to which it is linked in cis, and many of its properties are similar to those of enhancer elements (4). The abundance of hormonally induced transcripts and, in some cases, the ability of hormones to affect transcription at all appear to be a function of the chromosomal site of provirus insertion (9). Thus, there are apparently two levels at which viral transcription is regulated: the specific interaction of the glucocorticoid receptor with the GRE and a much less clearly defined position effect that may determine whether a productive interaction between the receptor and DNA can occur.

MMTV proviral DNA is endogenous to all inbred strains of mice and to many feral populations. These endogenous sequences are stable genetic elements; their number and genomic location are a characteristic of each inbred strain. Endogenous MMTV genes of many mouse strains are not actively transcribed. For example, C57BL/6 mice contain three apparently intact copies of proviral DNA (27), but MMTV RNA cannot be detected in any tissue, with the possible exception of lactating mammary gland, where small amounts of viral RNA have been detected in some studies $(19,39)$.

Surprisingly, hormone-inducible synthesis of MMTV RNA has been detected in the C57BL/6 T lymphoma cell line T1M1 $(21,34)$. These cells contain the endogenous units of MMTV proviral DNA present at the genetic loci $M t v-8$ (unit II), $M t v-9$ (unit III), and $M t v-17$ (unit XI) that are characteristic of other C57BL/6 cells in which viral RNA is not synthesized (27).

Experiments presented in this paper take advantage of the unique properties of $\mathrm{T} 1 \mathrm{M} 1$ cells to determine whether glucocorticoid-stimulated transcription can be correlated with alterations in the structure of MMTV chromatin and to begin to assess the possible role of altered chromatin conformations in programming the potential for transcriptional activation of the individual endogenous proviral genes.

\section{MATERIALS AND METHODS}

Cell culture. T1M1 is a T-cell lymphoma derived from the C57BL/6 mouse strain $(22,34)$. Cells were grown in suspension in Dulbecco modified Eagle medium (GIBCO Laboratories) containing $10 \%$ horse serum (KC Biologicals) in an atmosphere of $5 \% \mathrm{CO}_{2}$ saturated with water. Cell densities were maintained below $10^{6} / \mathrm{ml}$.

Preparation of nuclei. All steps in the preparation of nuclei were performed at 0 to $4^{\circ} \mathrm{C}$. Cells were washed twice in isotonic saline solution and then suspended in a hypotonic solution composed of $10 \mathrm{mM}$ Tris-hydrochloride ( $\mathrm{pH} 7.6), 10$ $\mathrm{mM} \mathrm{NaCl}$, and $3 \mathrm{mM} \mathrm{MgCl}$ at a cell density of $0.5 \times 10^{8}$ to $1 \times 10^{8}$ cells per ml. After $10 \mathrm{~min}$ on ice, cells were broken in a Dounce homogenizer fitted with a type A pestle. Cell breakage was monitored microscopically. Nuclei were pell- 


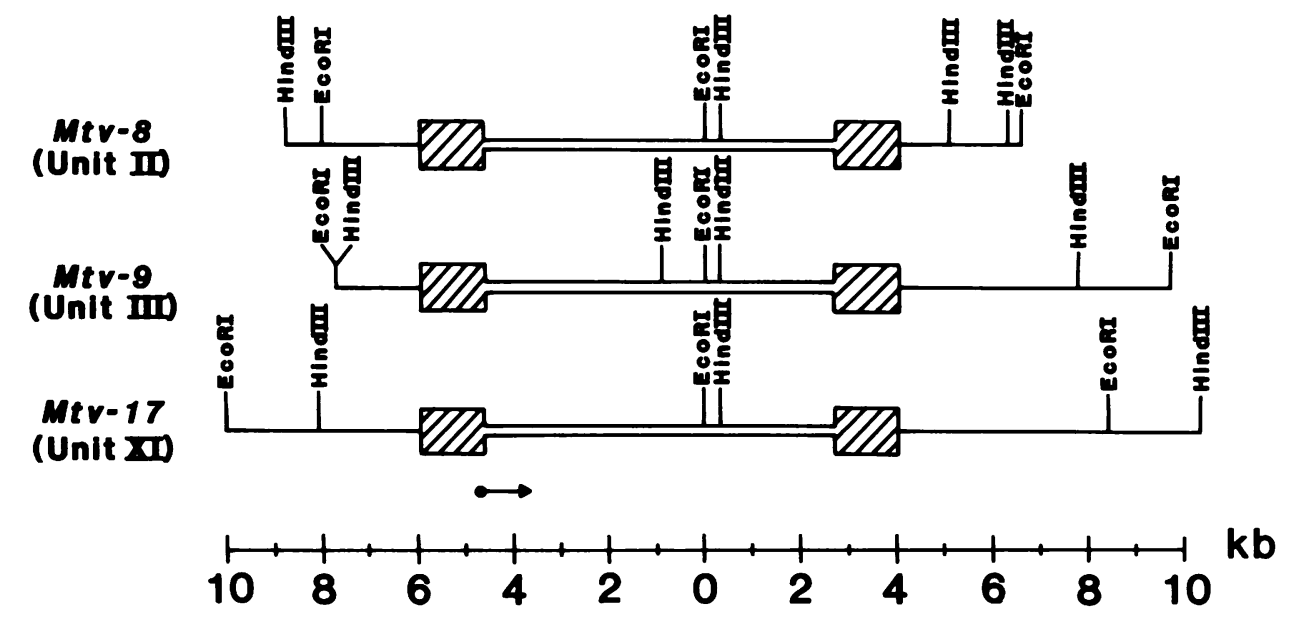

FIG. 1. Maps of MMTV DNA in T1M1 cells. MMTV sequences are shown as double lines; flanking DNA is shown as single lines. LTRs are indicated by hatched boxes. The arrow indicates the cap site and direction of MMTV RNA transcription. The restriction maps are taken from Peterson et al. (27).

eted by centrifugation at $100 \times g$ for $7 \mathrm{~min}$ and were washed twice in DNase I digestion buffer (20) $(10 \mathrm{mM}$ Tris-hydrochloride [pH 7.6], $0.1 \mathrm{M} \mathrm{NaCl}, 6 \mathrm{mM} \mathrm{MgCl}, 1 \mathrm{mM} 2-\mathrm{mer}$ captoethanol, and $0.1 \mathrm{mM}$ phenylmethylsulfonyl fluoride). Immediately preceding the final centrifugation step, the nuclei were counted in a hemacytometer, and the final nuclear suspension in DNase I digestion buffer was made at a density of $10^{7} / \mathrm{ml}$. Nuclei from cells that had been treated with dexamethasone before nuclear isolation were prepared with $10^{-7} \mathrm{M}$ dexamethasone in all solutions.

DNase I digestion of nuclei. Before treatment with DNase I, $\mathrm{CaCl}_{2}$ was added to the nuclear suspensions $\left(10^{7}\right.$ nuclei per $\mathrm{ml}$ in DNase I digestion buffer) to a final concentration of 1 $\mathrm{mM}$. Nuclei were then divided into portions of 1 to $2 \mathrm{ml}$ and incubated at $37^{\circ} \mathrm{C}$ for $5 \mathrm{~min}$ to ensure temperature equilibration. DNase I (Sigma Chemical Co.) was then added to a final concentration of 0 to $0.6 \mu \mathrm{g} / \mathrm{ml}$, and after $5 \mathrm{~min}$ at $37^{\circ} \mathrm{C}$ the digestions were terminated by addition of EDTA $(20$ $\mathrm{mM})$, sodium dodecyl sulfate $(0.5 \%)$, and proteinase $\mathrm{K}$ (50 $\mu \mathrm{g} / \mathrm{ml})$.

Preparation of DNA. DNA was purified from the DNase I-digested nuclei after proteinase $\mathrm{K}$ treatment for 12 to $16 \mathrm{~h}$ at $37^{\circ} \mathrm{C}$. The solutions were extracted twice with phenol$\mathrm{CHCl}_{3}$ (2:1) and once with $\mathrm{CHCl}_{3}$, and the DNA was then subjected to two successive ethanol precipitations, the second from $2.5 \mathrm{M}$ ammonium acetate. The DNA was suspended in $10 \mathrm{mM}$ Tris-hydrochloride ( $\mathrm{pH}$ 7.6)-1 mM EDT A at a final concentration of 100 to $200 \mu \mathrm{g} / \mathrm{ml}$. The concentration of each DNA sample was determined independently.

Plasmid DNA was purified from chloramphenicol-treated Escherichia coli HB101 or TB1 by the alkaline extraction method of Birnboim and Doly (1), followed by banding in a cesium chloride-ethidium bromide density gradient.

Southern blot analysis. Restriction endonucleases (Bethesda Research Laboratories) were used according to the recommendations of the supplier. Complete digestion of DNA was monitored by an internal standard of DNA from bacteriophage $\lambda$.

For Southern blot analysis (33), $10 \mu \mathrm{g}$ of restriction endonuclease-digested DNA was fractionated by electrophoresis through a $1 \%$ agarose gel. The gel was treated for 30 min with $0.5 \mathrm{M} \mathrm{NaOH}-1.5 \mathrm{M} \mathrm{NaCl}$, followed by $60 \mathrm{~min}$ of neutralization in $0.5 \mathrm{M}$ Tris-hydrochloride ( $\mathrm{pH} 7.6)-3 \mathrm{M}$ $\mathrm{NaCl}$. The DNA was then blotted onto nitrocellulose (Mill- ipore Corp. $)$ in $6 \times \mathrm{SSC}(1 \times \mathrm{SSC}$ is $0.15 \mathrm{M} \mathrm{NaCl}$ plus $15 \mathrm{mM}$ sodium citrate) for 12 to $24 \mathrm{~h}$. Filters were then air dried, baked for 2 to $3 \mathrm{~h}$ at $80^{\circ} \mathrm{C}$ in a vacuum oven, and hybridized as described below.

Molecular weight markers consisted of restriction fragments of cloned MMTV DNA whose sizes had been determined by comparison with HindIII-digested $\lambda$ DNA or restriction fragments of pBR322. The sizes of the markers are $14.1,12.4,10.7,9.8,8.0,6.5,6.0,4.7,4.4,2.0$, and 1.3 kilobases $(\mathrm{kb})$. All markers do not hybridize with all of the probes used in the Southern blot experiments.

Blot analysis of RNA. Total cellular RNA was isolated by dissolving washed cells in $6 \mathrm{M}$ guanidinium thiocyanate-50 mM 2-mercaptoethanol-0.5\% Sarkosyl-5 mM sodium citrate (pH 7.0) (3) and then selectively pelleting the RNA by centrifugation through $5.7 \mathrm{M} \mathrm{CsCl-0.1} \mathrm{M} \mathrm{EDTA} \mathrm{(11).} \mathrm{The}$ RNA pellets were dissolved in $10 \mathrm{mM}$ Tris-hydrochloride (pH 7.6)-1 mM EDTA and precipitated with ethanol.

RNA $(10 \mu \mathrm{g})$ was fractionated on a $1 \%$ agarose gel containing formaldehyde (17) and blotted to nitrocellulose (Millipore) in $20 \times \mathrm{SSC}$ (35). The filter was then air dried and baked for 2 to $3 \mathrm{~h}$ at $80^{\circ} \mathrm{C}$ in a vacuum oven. Just before hybridization as described below, the filter was washed briefly in $3 \times$ SSC to remove residual salt.

Filter hybridization. Blots were hybridized with ${ }^{32} \mathrm{P}$-labeled plasmid DNA nick translated as described by Feinstein et al. (9) to a specific activity of $1 \times 10^{8}$ to $3 \times 10^{8}$ $\mathrm{cpm} / \mu \mathrm{g}$. Specific hybridization conditions have been described previously (27).

Three different hybridization probes were utilized. A probe homologous to the entire MMTV genome consisted of a mixture of plasmids pMTV1 (37) and a subclone of the 5' portion of the proviral DNA located at $M t v-8$ designated pTC8 (27). The probe for indirect end labeling from the internal EcoRI site toward the 5' LTR was plasmid pMTV3.3, an EcoRI-BglII subclone of pMTV3 (18) inserted into the EcoRI-BamHI sites of pUC8 (40). Indirect end labeling from EcoRI toward the 3' LTR was accomplished with pMTV2.2, an EcoRI-PstI subclone of pMTV2 (25).

\section{RESULTS}

Hormone-inducible changes in MMTV chromatin. The sensitivity of proviral DNA to digestion by DNase I in isolated nuclei was used as an assay to probe the chromatin structure 
of MMTV genes in T1M1 cells. Maps of DNA comprising the genetic loci $M t v-8, M t v-9$, and $M t v-17$ that are present in T1M1 cells with restriction sites relevant to the present study are shown in Fig. 1. Nuclease sensitivity studies in other gene systems have revealed two kinds of altered chromatin structures associated with transcriptionally active (or potentially active) genes: a moderate sensitivity to the nuclease that usually extends throughout an entire active transcription unit $(41,42)$ and sometimes well beyond (16), and specific sites of nuclease hypersensitivity that are many times located within and around active genes (7).

Nuclei were prepared from T1M1 cells before and after a 9-h exposure to the synthetic glucocorticoid dexamethasone $\left(10^{-6} \mathrm{M}\right)$ and were digested briefly with various amounts of DNase I. DNA was then isolated, digested to completion with EcoRI, and subjected to Southern blot analysis. The extent of DNase I digestion was monitored by the size distribution of DNA fragments on agarose gel electrophoresis before restriction endonuclease cleavage. In each preparation of nuclei, comparable levels of digestion were obtained from a given concentration of DNase I. The Southern blots were probed with nick-translated DNA specific for the $5^{\prime}$ or 3' EcoRI fragments of the proviral units. These probes could be used to compare the moderate DNase I sensitivity of the six EcoRI fragments that contain proviral DNA relative to each other and also to map potential sites of DNase I hypersensitivity by indirect end labeling from the EcoRI site internal to each proviral unit (see Fig. 1 and 4).

The results of such an experiment utilizing a 5 '-specific probe are shown in Fig. 2, in which the most prominent bands are the expected $5^{\prime}$ EcoRI fragments of $10.0 \mathrm{~kb}$ $(M t v-17), 8.0 \mathrm{~kb}(M t v-8)$, and $7.7 \mathrm{~kb}(M t v-9)$. A site of hypersensitivity that is defined by a DNase I-generated subband of $4.8 \mathrm{~kb}$ was detectable in nuclei isolated from cells that had been treated for $9 \mathrm{~h}$ with dexamethasone (lanes e through $\mathrm{h}$ ); this hypersensitivity was significantly less apparent in nuclei from cells that had not been exposed to hormone (lanes a through d), indicating that glucocorticoid

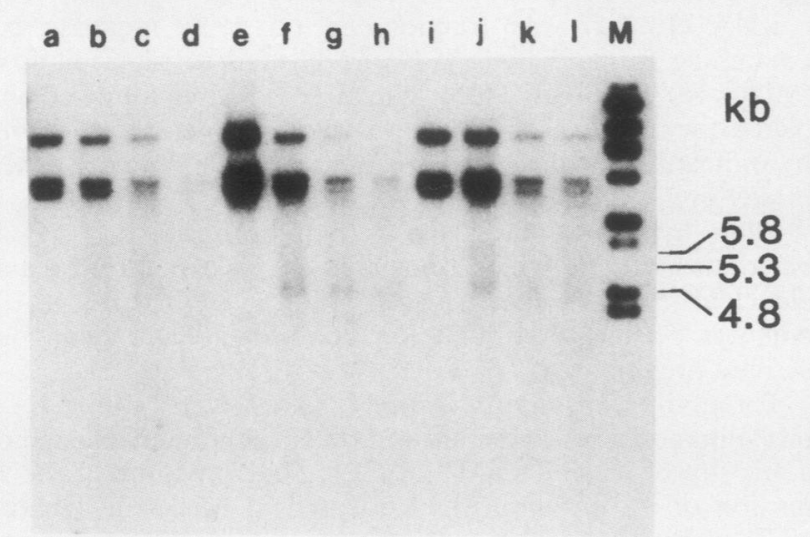

FIG. 2. DNase I sensitivity of the 5' portion of MMTV genes in T1M1 nuclei. Purified DNA $(10 \mu \mathrm{g})$ from DNase I-treated nuclei was digested to completion with EcoRI and subjected to Southern blot analysis with the $5^{\prime}$ probe indicated in Fig. 4 . Lanes a through d, Nuclei from cells not treated with dexamethasone; lanes e through $h$, dexamethasone $\left(10^{-6} \mathrm{M}\right)$ was added $9 \mathrm{~h}$ before preparation of nuclei; lanes $i$ through 1 , dexamethasone $\left(10^{-6} \mathrm{M}\right)$ was added immediately before preparation of nuclei; lane $\mathbf{M}$, size markers. Nuclei $\left(10^{7} / \mathrm{ml}\right)$ were treated with DNase I for $5 \mathrm{~min}$ at $37^{\circ} \mathrm{C}$ at a concentration of $0 \mu \mathrm{g} / \mathrm{ml}$ (lanes a, e, and i), $0.1 \mu \mathrm{g} / \mathrm{ml}$ (lanes b, f, and $\mathrm{j}$ ), $0.3 \mu \mathrm{g} / \mathrm{ml}$ (lanes c, g, and $\mathrm{k}$ ), or $0.6 \mu \mathrm{g} / \mathrm{ml}$ (lanes $\mathrm{d}, \mathrm{h}$, and $\mathrm{l}$ ) .

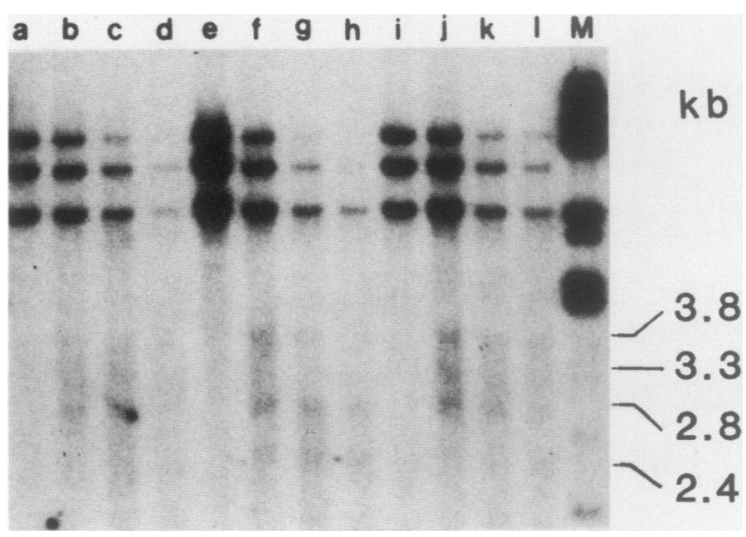

FIG. 3. DNase I sensitivity of the $3^{\prime}$ portion of MMTV genes in T1M1 nuclei. The nitrocellulose filter from the Southern blot experiment shown in Fig. 2 was probed with the 3 ' probe indicated in Fig. 4. Lanes are identical to those in the legend to Fig. 2.

induction of proviral gene transcription is indeed associated with demonstrable changes in chromatin structure. In addition, two other sites of extremely weak hypersensitivity were detectable and are defined by subbands of 5.8 and 5.3 $\mathrm{kb}$. These sites did not appear to be markedly enhanced after dexamethasone treatment, and although they were extremely weak, they were reproducibly seen in several preparations of nuclei (e.g., see Fig. 6).

The analogous experiment utilizing a 3 '-specific probe is shown in Fig. 3, and the expected 3' EcoRI fragments of 9.7 $\mathrm{kb}(M t v-9), 8.4 \mathrm{~kb}(M t v-17)$, and $6.6 \mathrm{~kb}(M t v-8)$ are apparent. In addition, there are four rather diffuse DNase I-generated subbands of $3.8,3.3,2.8$, and $2.4 \mathrm{~kb}$. Although all of the subbands were detectable in nuclei from cells that had not "been exposed to hormone (lanes a through d), the intensity of the 3.8- and 2.4-kb bands markedly increased after dexamethasone treatment (lanes e through h).

The positions of these DNase I-hypersensitive sites with respect to MMTV sequences are shown in Fig. 4 . The three $5^{\prime}$ sites and three of the four $3^{\prime}$ sites map to analogous positions within the 5' and 3' LTRs of proviral DNA; two sites span the GRE and the third is located ca. 500 bp away
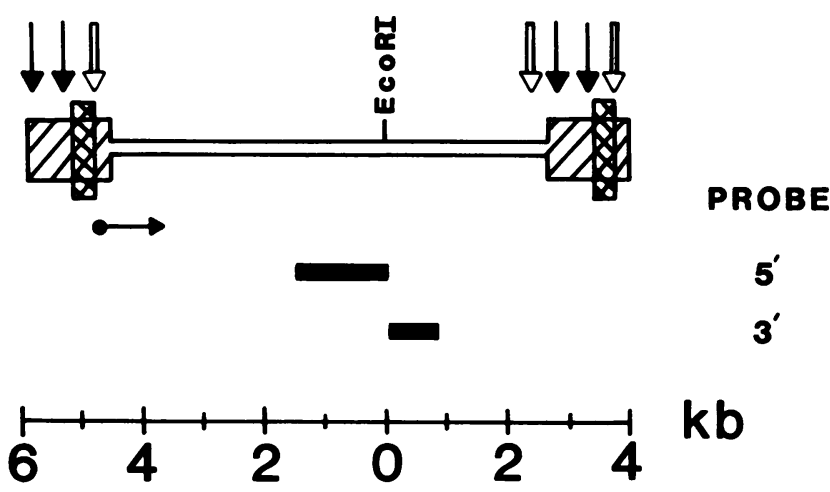

FIG. 4. DNase I-hypersensitive sites in MMTV genes. LTRs are shown as hatched boxes. Areas of cross-hatching represent GREs. The horizontal arrow defines the cap site and direction of viral RNA transcription. Indirect-end-labeling probes are indicated. Type I sites are shown as open vertical arrows; type II sites are shown as solid vertical arrows. See the text for a description of type I and type II sites. 


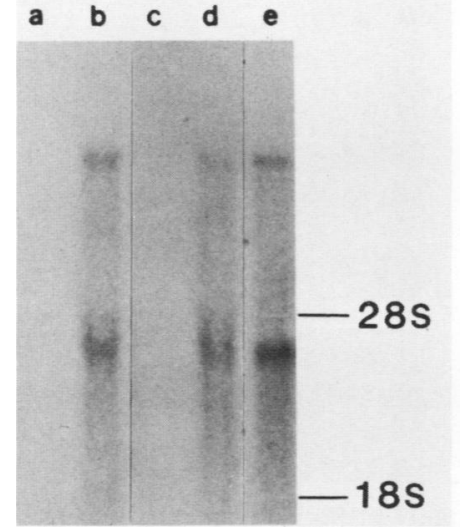

FIG. 5. Hormone-inducible synthesis of MMTV RNA in T1M1 cells. Total cellular RNA (10 $\mu \mathrm{g}$ in lanes a through d; $1 \mu \mathrm{g}$ in lane e) was fractionated by agarose gel electrophoresis in the presence of formaldehyde, blotted to nitrocellulose, and probed with nick-translated DNA representing the entire MMTV genome. RNA was prepared from T1M1 cells treated with dexamethasone $\left(10^{-6} \mathrm{M}\right)$ as follows: lane a, no dexamethasone; lane $b$, dexamethasone for $9 \mathrm{~h}$; lane $\mathrm{c}$, dexamethasone for $9 \mathrm{~h}$, and then cells were cultured without dexamethasone for approximately six cell generations; lane d, same as lane $\mathrm{c}$ with dexamethasone present during the last $9 \mathrm{~h}$. Lane $\mathrm{e}$ contains RNA from dexamethasone-treated M1.54, a clone of MMTV-infected rat hepatoma cells (43).

in the $5^{\prime}$ direction. The fourth $3^{\prime}$ site maps to a position within proviral DNA in, or very near, a glucocorticoid receptor binding site that has been defined in vitro (25).

In addition to changes in hypersensitivity, another feature of the DNase I digestion of nuclei from dexamethasonetreated cells is the apparent differential nuclease sensitivity of the six EcoRI restriction fragments. In particular, two restriction fragments $8.0 \mathrm{~kb}\left(5^{\prime}\right.$; Fig. 2) and $6.6 \mathrm{~kb}\left(3^{\prime} ;\right.$ Fig. 3) in size are comparatively resistant to DNase I; these fragments correspond to the $5^{\prime}$ and $3^{\prime}$ portions of the proviral unit (unit II) located at $M t v-8$. This differential sensitivity may be due to the lack of hypersensitive sites in this proviral unit, or it may reflect differences between the three proviral units in the kind of general, more moderate nuclease sensitivity that extends throughout active transcription units.

Glucocorticoid-mediated activation of MMTV gene transcription occurs very rapidly; the rate of MMTV RNA synthesis is half-maximal after 8 to $9 \mathrm{~min}$ of hormone treatment (38). If the hormone-mediated changes in chromatin structure described above are a significant feature of gene activation, they would be expected to occur very rapidly. To examine this point, a culture of T1M1 cells was split, a portion was used to prepare the nuclei analyzed in Fig. 2 and 3 , lanes a through $d$ (no dexamethasone treatment), and dexamethasone $\left(10^{-6} \mathrm{M}\right)$ was added to the remainder. The hormone-treated cells were then immediately placed on ice, and nuclei were prepared for DNase I digestion, a process taking ca. $1 \mathrm{~h}$ (at 0 to $4^{\circ} \mathrm{C}$ ). As shown in Fig. 2 and 3, lanes $i$ through 1 , there was essentially no difference in the pattern or intensity of the hypersensitive sites between this very brief hormone treatment and one that extended for $9 \mathrm{~h}$ (lanes e through h). Thus, the hormone-mediated alterations in DNase I hypersensitivity occur very rapidly. In contrast, the differences in the general nuclease sensitivity of the proviral units that were apparent after longer dexamethasone treatment were not seen with the short exposure to hormone, suggesting that these changes may require relatively long, continuous exposure to glucocorticoids before they occur.
Stability of hormone-induced chromatin alterations. To assess the stability of the hormone-induced changes in chromatin structure, T1M1 cells were treated for $9 \mathrm{~h}$ with $10^{-6} \mathrm{M}$ dexamethasone (the same culture analyzed in Fig. 2 and 3 , lanes e through $h$ ), and the cells were then washed until the dexamethasone concentration was less than $10^{-14}$ $M$. The washed cells were propagated for approximately six cell generations, at which time dexamethasone $\left(10^{-6} \mathrm{M}\right)$ was again added to a portion of the culture.

These conditions led to an induction of MMTV RNA during the first hormone treatment (Fig. 5, lanes a and b), a loss of detectable viral RNA synthesis during hormone withdrawal (lane $c$ ), and reinduction when hormone was added a second time (lane d). The results in Fig. 5 also serve to demonstrate that there is nothing grossly aberrant in the expression of endogenous MMTV genes in T1M1 cells. The two MMTV RNAs that can be detected are identical in size to RNAs synthesized in MMTV-infected rat hepatoma cells (Fig. 5, lane e). With the $28 \mathrm{~S}$ and $18 \mathrm{~S}$ rRNAs as markers, the two MMTV RNA molecules are ca. 8.8 and $3.6 \mathrm{~kb}$ in size, corresponding to MMTV genomic RNA that is the primary transcript of proviral DNA and a spliced product, respectively.

Nuclease sensitivity of MMTV chromatin after hormone withdrawal and secondary stimulation is shown in Fig. 6 and 7. Hypersensitivity at the $5^{\prime}$ site defined by the $4.8-\mathrm{kb}$ subband was diminished after hormone withdrawal (Fig. 6, lanes a through $\mathrm{c}$ ), becoming comparable to that seen in nuclei prepared from cells that had not been exposed to dexamethasone (Fig. 2, lanes a through d). In like fashion the hypersensitive site at the analogous position in the $3^{\prime}$ LTR (defined by the 3.8-kb subband) was less apparent after hormone withdrawal, as was the site defined by the 2.4-kb subband (Fig. 7, lanes a through c). These sites reappeared when dexamethasone was added to withdrawn cells, and MMTV RNA synthesis was again induced (Fig. 6 and 7, lanes $d$ through $f$ ). These hypersensitive sites whose presence correlates with the presence of glucocorticoids have

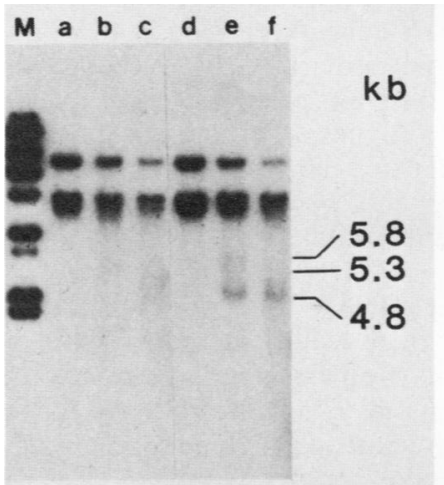

FIG. 6. Stability of hormone-induced changes in MMTV chromatin in the $5^{\prime}$ LTR. Purified DNA $(10 \mu \mathrm{g})$ from DNase I-treated T1M1 nuclei was digested to completion with EcoRI and subjected to Southern blot analysis with the 5 ' probe indicated in Fig. 4. Cells were treated with dexamethasone $\left(10^{-6} \mathrm{M}\right)$ for $9 \mathrm{~h}$ (the same culture analyzed in Fig. 2 and 3, lanes e through h), washed, and then propagated in the absence of hormone for approximately six cell generations. Lane M, Size markers; lanes a through c, no further dexamethasone treatment; lanes $\mathrm{d}$ through $\mathrm{f}$, dexamethasone $\left(10^{-6}\right.$ M) was added $9 \mathrm{~h}$ before preparation of the nuclei. Nuclei $\left(10^{7} / \mathrm{ml}\right)$ were treated with DNase I for $5 \mathrm{~min}$ at $37^{\circ} \mathrm{C}$ at a concentration of 0 $\mu \mathrm{g} / \mathrm{ml}$ (lanes a and d), $0.1 \mu \mathrm{g} / \mathrm{ml}$ (lanes b and e), or $0.3 \mu \mathrm{g} / \mathrm{ml}$ (lanes $\mathrm{c}$ and $\mathrm{f}$. 
been termed type I hypersensitive sites, and they are indicated by open arrows in Fig. 4. In contrast to type I sites, the nuclease hypersensitivity that is defined by subbands of 5.8 and $5.3 \mathrm{~kb}\left(5^{\prime}\right)$ and 3.3 and $2.8 \mathrm{~kb}\left(3^{\prime}\right)$ appears not to be markedly hormone dependent. These sites have been designated type II hypersensitive sites and are shown by solid arrows in Fig. 4.

\section{DISCUSSION}

The results presented here demonstrate that altered chromatin conformations of endogenous MMTV proviral DNA can be defined by their sensitivity to DNase I in isolated nuclei. The altered conformations are reflected in specific sites of DNase I hypersensitivity, as well as in differential moderate nuclease sensitivity of entire proviral transcription units.

The observed hypersensitive sites are of two types. Type I hypersensitive sites are those that are induced in the presence of glucocorticoid hormones, and they regress and reappear coinciding with periods of hormone withdrawal and readdition. The type I sites map within, or very near, DNA sequences that comprise specific in vitro binding sites for the glucocorticoid receptor, and it is tempting to speculate that these sites are a direct result of receptor binding. Interestingly, even in the absence of glucocorticoids, weak DNase I hypersensitivity is associated with type I sites. It is conceivable that this weak hypersensitivity is indicative of receptor that is bound at these sites in the absence of hormone; specific in vitro binding of receptor to GRE sequences in the absence of hormone has not been examined. Type II sites are not markedly hormone dependent. They map to corresponding positions within the $5^{\prime}$ and $3^{\prime}$ LTR sequences, ca. 500 and $1,000 \mathrm{bp}$ to the $5^{\prime}$ side of the type I site that is in or near the GRE. These type II sites may serve to mark one or more of the proviral units for hormone activation. By this view the type II hypersensitive sites may be indicative of molecular signals that program $\mathrm{T} 1 \mathrm{M} 1$ cells to allow a productive interaction between the receptor-hormone complex and GRE sequences that are normally not recognized in C57BL/6 cells, resulting in the unusual phenotype of endogenous MMTV gene expression in T1M1. Type II sites in the 5' LTR are particularly weak, although they are reproducibly seen in different preparations of nuclei. To some extent this may be a reflection of the fact that these sites are distal to the indirect-end-labeling probe (Fig. 4). If multiple DNase I cleavage events occur in a single LTR, the intensity of subbands generated by sites most distal to the probe will be decreased.

All of the DNase I-generated subbands are relatively diffuse; the band width increases with decreasing size of subband, and in all cases it corresponds to ca. 100 to $200 \mathrm{bp}$ of DNA. This may indicate that the nuclease recognizes a chromatin domain that extends over a DNA region of this size and cleaves relatively nonspecifically within this domain. Evidence suggests that this is the case for the nuclease-hypersensitive region near the $5^{\prime}$ end of the chicken $\beta$-globin gene (20), where nuclease hypersensitivity appears to result from a DNA sequence that is free of nucleosomes and that instead may be associated with a specific protein that is required for the in vitro assembly of chromatin that contains the hypersensitive domain (8).

The presence of the three endogenous proviral units in T1M1 (see Fig. 1) potentially allows examination of the extent to which the site of provirus insertion plays a role in the observed chromatin conformations. Perhaps the clearest statement that can be made in this regard is based on the

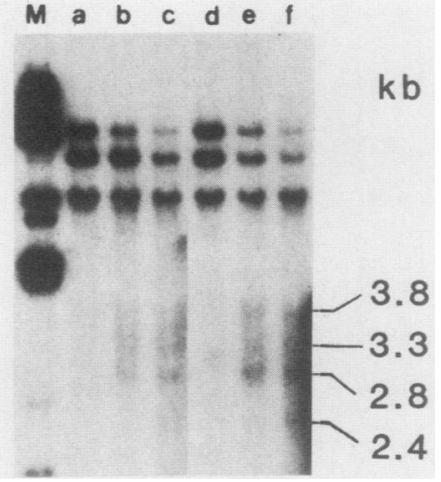

FIG. 7. Stability of hormone-induced changes in MMTV chromatin in and near the $3^{\prime}$ LTR. The nitrocellulose filter from the Southern blot experiment shown in Fig. 6 was probed with the $3^{\prime}$ probe indicated in Fig. 4. Lanes are identical to those in the legend to Fig. 6.

relative DNase I resistance of proviral DNA located at $M t v-8$ (unit II; Fig. 2 and 3). Cloned $M t v-8$ DNA from T1M1 that has been transfected into mouse or rat cells is able to specify glucocorticoid-regulated transcription, indicating that this endogenous provirus contains a functional hormone-responsive promoter (P. Burdick and D. Peterson, unpublished data). Thus, the relative DNase I resistance of this endogenous unit apparently does not result from an inherent inability to be recognized as a hormone-responsive gene and suggests that the cells are able to maintain distinct chromatin structures that are determined by factors related to the site of provirus insertion and not by the nature of the transcription unit itself. With regard to the presence of DNase I hypersensitive sites in the individual proviral units, the experiments presented here have not specifically addressed the question of which of these units actually contains type I or type II sites or whether these sites are present simultaneously in the $5^{\prime}$ and $3^{\prime}$ LTRs of a single proviral unit; the indirect-end-labeling experiments were performed with probes internal to the MMTV genome. However, the subband of $4.8 \mathrm{~kb}$ that defines the type I site in the 5' LTR does not contain the HindIII site that is present only in the $5^{\prime}$ EcoRI fragment of $M t v-9$ (unpublished data), and the relative DNase I resistance of the EcoRI restriction fragments containing the proviral unit at $M t v-8$ suggests that this provirus does not contain hypersensitive sites. Thus, it seems most likely that the observed sites of DNase I hypersensitivity are primarily located within proviral DNA at $M t v-17$. It has not been determined which proviral unit(s) is transcriptionally active in T1M1 cells.

Hormone-induced changes in MMTV chromatin are not unique to T1M1 cells. Preliminary observations indicate that sites of DNase I hypersensitivity similar to those described here for T1M1 are present in cells exogenously infected with MMTV (unpublished data). In addition, Zaret and Yamamoto (44), utilizing transfected mouse L cells, reported the presence of sites of DNase I hypersensitivity within $5^{\prime}$ and 3' MMTV LTR sequences present in a MMTV-herpes simplex virus $t k$ gene construct. These sites are very similar to the type I and type II sites seen in T1M1 cells; however, their work revealed only one type I site (within the GRE) and one type II site in each LTR, and their construction did not contain DNA sequences that comprise the receptor-binding site that is not in the LTR and where a type I site has been mapped in T1M1 (see Fig. 4).

Similar to the results reported here, changes in chromatin 
structure are associated with estrogen activation of the chicken vitellogenin II gene (2). In liver cells this gene is marked internally and in 3' flanking sequences with sites of nuclease hypersensitivity before hormone treatment; these are analogous to the type II sites described here. When 17 $\beta$-estradiol is administered, three new hypersensitive sites are induced on the $5^{\prime}$ side of the gene. Two of these sites are apparently stably maintained through cell division in the absence of the continuous presence of the hormone, and the third site is present only during periods of hormone treatment and, analogous to type I sites in MMTV DNA, it maps to a DNA sequence that contains a specific in vitro binding site for the estrogen receptor (15).

One attractive view is that gene activation by steroid hormones occurs by a mechanism similar to that of transcriptional enhancer elements (4). Indeed, indirect experiments have shown that activity of the simian virus 40 enhancer element depends on its interaction with a trans-acting cellular factor, presumably a protein (32). Such factors could be the functional analogs of hormone-activated steroid receptors. Furthermore, like the nuclease hypersensitivity associated with specific steroid receptor binding sites, hypersensitivity has been shown to be associated with enhancer elements in simian virus $40(6,30)$, polyoma $(14)$, and immunoglobulin genes $(5,23,24)$. It seems likely that these altered chromatin structures may reflect, or actually encode, important mechanistic features of these regulatory DNA sequences.

\section{ACKNOWLEDGMENTS}

I thank Stuart Feinstein for invaluable help in the early stages of this work and Katherine Kriz Beifuss for expert technical assistance. I also thank members of my laboratory for helpful discussions and for providing plasmid constructions and Stuart Wright for expert preparation of the manuscript.

This work was supported by Public Health Service grant CA32695 from the National Cancer Institute and grant A-904 from the Robert A. Welch Foundation. This work was also partially funded by the Texas Agricultural Experiment Station.

\section{LITERATURE CITED}

1. Birnboim, H. C., and J. Doly. 1979. A rapid alkaline extraction procedure for screening recombinant plasmid DNA. Nucleic Acids Res. 7:1513-1523.

2. Burch, J. B. E., and H. Weintraub. 1983. Temporal order of chromatin structural changes associated with activation of the major chicken vitellogenin gene. Cell 33:65-76.

3. Chirgwin, J. M., A. E. Przybyla, R. J. MacDonald, M. J. Cowan, W. J. Rutter, and M. W. Kirschner. 1979. Isolation of biologically active ribonucleic acid from sources enriched in ribonuclease. Biochemistry 18:5294-5299.

4. Chandler, V. L., B. A. Maler, and K. R. Yamamoto. 1983. DNA sequences bound specifically by glucocorticoid receptor in vitro render a heterologous promoter hormone responsive in vivo. Cell 33:489-499.

5. Chung, S.-Y., V. Folsom, and J. Wooley. 1983. DNaseI-hypersensitive sites in the chromatin of immunoglobulin $\kappa$ light chain genes. Proc. Natl. Acad. Sci. U.S.A. 80:2427-2431.

6. Cremisi, C. 1981. The appearance of DNasel hypersensitive sites at the $5^{\prime}$ end of the late SV40 genes is correlated with the transcriptional switch. Nucleic Acids Res. 9:5949-5964.

7. Elgin, S. C. R. 1981. DNaseI hypersensitive sites of chromatin. Cell 27:413-415.

8. Emerson, B. M., and G. Felsenfeld. 1984. Specific factor conferring nuclease hypersensitivity at the $5^{\prime}$ end of the chicken adult $\beta$-globin gene. Proc. Natl. Acad. Sci. U.S.A. 81:95-99.

9. Feinstein, S. C., S. R. Ross, and K. R. Yamamoto. 1982. Chromosomal position effects determine transcriptional potential of integrated mammary tumor virus DNA. J. Mol. Biol. 156:
$549-566$

10. Geisse, S., C. Scheidereit, H. M. Westphal, N. E. Hynes, B. Groner, and M. Beato. 1982. Glucocorticoid receptors recognize DNA sequences in and around murine mammary tumor virus DNA. EMBO J. 1:1613-1619.

11. Glisin, V., R. Cryvenjakov, and C. Byus. 1974. Ribonucleic acid isolated by cesium chloride centrifugation. Biochemistry 3: 2633-2637.

12. Govindan, M. V., E. Spiess, and J. Majors. 1982. Purified glucocorticoid receptor-hormone complex from rat liver cytosol binds specifically to cloned mouse mammary tumor virus long terminal repeats in vitro. Proc. Natl. Acad. Sci. U.S.A. 79:5157-5161.

13. Grove, J. R., B. S. Dieckman, T. A. Schroer, and G. M. Ringold. 1980. Isolation of glucocorticoid-unresponsive rat hepatoma cells by fluorescence-activated cell sorting. Cell 21:47-56.

14. Herbomel, P., S. Saragosti, D. Blangy, and M. Yaniv. 1981. Fine structure of the origin-proximal DNAase I-hypersensitive region in wild-type and EC mutant polyoma. Cell 25:651-658.

15. Jost, J.-P., M. Seldran, and M. Geiser. 1984. Preferential binding of estrogen-receptor complex to a region containing the estrogen-dependent hypomethylation site preceding the chicken vitellogenin II gene. Proc. Natl. Acad. Sci. U.S.A. 81:429-433.

16. Lawson, G. M., B. J. Knoll, C. J. March, S. L. Woo, M.-J. Tsai, and B. W. O'Malley. 1982. Definition of $5^{\prime}$ and $3^{\prime}$ structural boundaries of the chromatin domain containing the ovalbumin multigene family. J. Biol. Chem. 257:1501-1507.

17. Lehrach, H., D. Diamond, J. M. Wozney, and H. Boedtker. 1977. RNA molecular weight determinations by gel electrophoresis under denaturing conditions, a critical reexamination. Biochemistry 16:4743-4751.

18. Majors, J. E., and H. E. Varmus. 1981. Nucleotide sequences at host-proviral junctions for mouse mammary tumor virus. Nature (London) 289:253-258.

19. Marcus, S. L., S. W. Smith, and N. H. Sarkar. 1981. Quantitation of murine mammary tumor virus-related RNA in mammary tissues of low- and high-mammary-tumor-incidence mouse strains. J. Virol. 40:87-95.

20. McGhee, J. D., W. I. Wood, M. Dolan, J. D. Engel, and G. Felsenfeld. 1981. A 200 bp region at the $5^{\prime}$ end of the chicken adult $\beta$-globin gene is accessible to nuclease digestion. Cell 27:45-55.

21. Mermod, J.-J., S. Bourgeois, N. Defer, and M. Crépin. 1983. Demethylation and expression of murine mammary tumor proviruses in mouse thymoma cell lines. Proc. Natl. Acad. Sci. U.S.A. 80:110-114.

22. Mermod, J.-J., L. Intrière, C. MacLeod, and S. Bourgeois. 1981. Characterization of a new type of thymoma variants supersensitive to dexamethasone. J. Steroid Biochem. 15:25-34.

23. Mills, F. C., L. M. Fisher, R. Kuroda, A. M. Ford, and H. J. Gould. 1983. DNasel hypersensitive sites in the chromatin of human $\mu$ immunoglobulin heavy-chain genes. Nature (London) 306:809-812.

24. Parslow, G. T., and D. K. Granner. 1982. Chromatin changes accompany immunoglobulin $\kappa$ gene activation: a potential control region within the gene. Nature (London) 299:449-451.

25. Payvar, F., D. DeFranco, G. L. Firestone, B. Edgar, Ö. Wrange, S. Okret, J.-Å. Gustafsson, and K. R. Yamamoto. 1983. Sequence-specific binding of glucocorticoid receptor to MTV DNA at sites within and upstream of the transcribed region. Cell 35:381-392.

26. Payvar, F., Ö. Wrange, J. Carlstedt-Duke, S. Okret, J.-Å. Gustafsson, and K. R. Yamamoto. 1981. Purified glucocorticoid receptors bind selectively in vitro to a cloned DNA fragment whose transcription is regulated by glucocorticoids in vivo. Proc. Natl. Acad. Sci. U.S.A. 78:6628-6632.

27. Peterson, D. O., K. G. Kriz, J. E. Marich, and M. G. Toohey. 1985. Sequence organization and molecular cloning of mouse mammary tumor virus DNA endogenous to C $57 \mathrm{BL} / 6$ mice. J. Virol. 54:525-531.

28. Pfahl, M. 1982. Specific binding of the glucocorticoid-receptor complex to the mouse mammary tumor proviral promoter region. Cell 31:475-482. 
29. Ringold, G. M., K. R. Yamamoto, J. M. Bishop, and H. E. Varmus. 1977. Glucocorticoid-stimulated accumulation of mouse mammary tumor virus RNA: increased rate of synthesis of viral RNA. Proc. Natl. Acad. Sci. U.S.A. 74:2879-2883.

30. Saragosti, S., S. Cereghini, and M. Yaniv. 1982. Fine structure of the regulatory region of simian virus 40 minichromosomes revealed by DNAaseI digestion. J. Mol. Biol. 160:133-146.

31. Scheidereit, C., S. Geisse, H. M. Westphal, and M. Beato. 1983. The glucocorticoid receptor binds to defined nucleotide sequences near the promoter of mouse mammary tumor virus. Nature (London) 304:749-752.

32. Schöler, H. R., and P. Gruss. 1984. Specific interaction between enhancer-containing molecules and cellular components. Cell 36:403-411.

33. Southern, E. M. 1975. Detection of specific sequences among DNA fragments separated by gel electrophoresis. J. Mol. Biol. 98:503-517.

34. Stallcup, M. R., J. C. Ring, D. S. Ucker, and K. R. Yamamoto. 1979. Mammary tumor virus genes: probes for mechanisms of transcriptional regulation. Cold Spring Harbor Conf. Cell Proliferation 6:919-936.

35. Thomas, P. S. 1980 . Hybridization of denatured RNA and smal DNA fragments transferred to nitrocellulose. Proc. Natl. Acad. Sci. U.S.A. 77:5201-5205.

36. Ucker, D. S., G. L. Firestone, and K. R. Yamamoto. 1983. Glucocorticoids and chromosomal position both modulate murine mammary tumor transcription by affecting the efficiency of promoter utilization. Mol. Cell. Biol. 3:551-561.

37. Ucker, D. S., S. R. Ross, and K. R. Yamamoto. 1981. Mammary tumor virus DNA contains sequences required for its hormone regulated transcription. Cell 27:257-266.

38. Ucker, D. S., and K. R. Yamamoto. 1984. Early events in the stimulation of mammary tumor virus RNA synthesis by glucocorticoids. Novel assays of transcription rates. J. Biol. Chem. 259:7416-7420.

39. Varmus, H. E., N. Quintrell, E. Medeiros, J. M. Bishop, R. C. Nowinski, and N. H. Sarkar. 1973. Transcription of mouse mammary tumor virus genes in tissues from high and low tumor incidence mouse strains. J. Mol. Biol. 79:663-679.

40. Viera, J., and J. Messing. 1982. The pUC plasmids, an M13mp7derived system for insertion mutagenesis and sequencing with synthetic universal primers. Gene 19:259-268.

41. Weintraub, H., and M. Groudine. 1976. Chromosomal subunits in active genes have an altered conformation. Science 193: 848-856.

42. Weisbrod, S. 1982. Active chromatin. Nature (London) 297: 289-295.

43. Yamamoto, K. R., M. R. Stallcup, J. Ring, and G. M. Ringold. 1978. Mammary tumor virus DNA: a glucocorticoid-responsive transposable element. Cold Spring Harbor Symp. Quant. Biol. 42:625-638.

44. Zaret, K. S., and K. R. Yamamoto. 1984. Reversible and persistent changes in chromatin structure accompany activation of a glucocorticoid-dependent enhancer element. Cell 38:29-38. 